\title{
Studies on the changes of biochemical, microbiological and sensory parameters of sauerkraut and fermented mix vegetables
}

\author{
*Ghosh, D. \\ Barrackpore Rastraguru Surendranath College, 85, Middle Road and 6, Riverside Road, Barrackpore, \\ Kolkata-700120, India
}

\author{
Article history: \\ Received: 26 April 2020 \\ Received in revised form: 27 \\ May 2020 \\ Accepted: 2 June 2020 \\ Available Online: 22 \\ November 2020

\section{Keywords:} \\ Sauerkraut, \\ Mixed vegetable, \\ Lactic acid bacteria, \\ Vitamin B, \\ Fermentation.
}

\section{DOI:}

https://doi.org/10.26656/fr.2017.5(1).193

\begin{abstract}
Fermentation is one of the safest and most economical means of producing foods acceptable to human beings. It improves the nutritional quality of foods by increasing the bioavailability and thus, renders the food safe palatable and easily acceptable to mankind. The present study showed the effects of fermentation on the nutritional quality and safety of fermented foods with respect to nutrient composition and digestibility measures. Sauerkraut and fermented mixed vegetable were selected for study and the effects of fermentation on nutrient were observed. Digestibility, shelf-life and biochemical aspects were also studied. Level of all principle nutrients was significantly increased. In course of fermentation, total sugar and reducing sugar in the brine increased slowly to $3 \%$ and $2 \%$, respectively up to 8 th day and then decreased in sauerkraut fermentation. The maximum total acidity (1.98-2.22\%) was observed on 15th day in fermented mixed vegetables. The $\mathrm{pH}$ of the shredded cabbage was 6.9 and decreased to around 4 after 15 days and then remained constant.
\end{abstract}

\section{Introduction}

Fermentation is the process of deriving energy from the oxidation of organic compounds, such as carbohydrates and using an endogenous electron acceptor, which is usually an organic compound (Ivey, 2018). Most fermentation processes are activated either by molds, yeasts, or bacteria, working singularly or together. The great majority of these microorganisms come from a relatively small number of genera (Bartoszek et al., 2002).

Fermented vegetables begin with lactofermentation, a method of food preservation that also enhances the nutrient content of the food. The action of the bacteria makes the minerals in cultured foods more readily available to the body. The bacteria also produce vitamins and enzymes that are beneficial for digestion. Almost any vegetable can be fermented, and fermenting farm-fresh produce is a great way to provide good nutrition. Fermentation of vegetable alone or a mixture of different kinds, along with herbs and spices, provide a great variety of nutrient foods (Ciska and Pathak, 2004).

Sauerkraut is prepared by shredding cabbage in the presence of $2-3 \%(\mathrm{v} / \mathrm{v})$ of salt. It contains, upon completion of the fermentation, not less than $1 \%$ and
$1.5 \%$ of acid, expressed as lactic acid (Amin and Lee, 2005).

In terms of food processing, vegetables are classified as low acid foods due to their lower levels of acidity. Low acid foods are more prone to deterioration by micro -organisms and can in fact provide an ideal substrate for food poisoning organisms when in a moist environment. Low acid foods can be safely preserved by making them more acidic, either through pickling or salting or drying (Davey et al., 2000.There are several ways to prepare the vegetables for fermenting: grating, shredding, chopping, slicing, or leaving whole. The preparation method is a personal choice, though some vegetables are better suited for leaving whole, while others ferment better when shredded or grated (Panesar, 2011).

In America and European countries, Sauerkraut is very popular. It is often eaten as an adjuvant with other foods to make them more digestive and increase the flavor of other foods. Isothiocyanates produced during Sauerkraut fermentation prevent the growth of cancer cells (Peñas et al., 2012).

Cabbage is grown and available in most of the parts of the country in India. It is used both as raw salad and cooked vegetable. The natural fermentation of cabbage 
may result in spoilage if desired lactic acid bacteria are not present in sufficient numbers (Van Garde et al., 1994). The development of specific starter cultures with desirable bacteria is of prime importance to achieve consistent quality of the Sauerkraut. The present research work was designed to prepare the sauerkraut by natural fermentation. With the period of fermentation proceeds, how the biochemical changes in terms of B vitamin, protein content, flavonoid, alkaloid occur in sauerkraut and fermented mixed vegetable was observed. Addition of raw vegetables were made to form nutritionally enriched mixed fermented vegetable that was better acceptable by the consumers from its sensory evaluation.

\section{Materials and methods}

\subsection{Preparation of sample}

\subsubsection{Sauerkraut preparation}

At first, fresh cabbage was taken; it was then shredded of approximately $2.5 \mathrm{~mL}$ of thickness. About $2 \%$ to $3 \%(\mathrm{w} / \mathrm{w})$ of salt $(\mathrm{NaCl})$ was added. The mixture was covered and sealed. Uniform pressure was applied on the cover so that fermentation would occur properly (Amin and Lee, 2005).

\subsubsection{Mix vegetable preparation}

Fresh carrot, bean, broccoli, capsicum and tomato were taken as raw vegetables; those were shredded (2.5 $\mathrm{mL}$ thick). Salt $(2 \%$ to $3 \% \mathrm{w} / \mathrm{w})$ was added and the mixture was covered and sealed. Pressure was applied on it for the fermentation process to be carried on properly (Amin and Lee, 2005).

\subsection{Microbiological analysis}

\subsubsection{Culture development and maintenance}

Lactobacillus plantarum strain 201 LRR (NDRI Karnal, India) was sub-cultured twice at $30^{\circ} \mathrm{C}$ in MRS broth. The culture was grown in MRS broth for $48 \mathrm{hrs}$ before inoculation, the culture was centrifuged at 10,000 $\mathrm{x} g$ and the pellet obtained was washed twice with sterilized normal saline $(0.85 \% \mathrm{w} / \mathrm{v} \mathrm{NaCl})$. Finally, the pellet was re-suspended in $200 \mathrm{~mL}$ sterile fresh normal saline for further use.

\subsubsection{Fermentation process}

The fermentation was carried out in the month of December-January when the room temperature was around $20^{\circ} \mathrm{C}$ for 15 days till the $\mathrm{pH}$ reached around 4.0 and total acidity was achieved. When total acidity became constant, the bottles were kept in refrigerator for storage at $6-8^{\circ} \mathrm{C}$ (De Man et al., 1960).

\subsubsection{Enumeration of microorganisms}

Samples of brine were withdrawn in triplicate from each bottle using $1 \mathrm{~mL}$ sterile glass pipettes. Samples were diluted by serial dilution technique and $0.5 \mathrm{~mL}$ aliquot of appropriate dilution was spread on two types of media in triplicate. The plates containing MRS medium were incubated at $37^{\circ} \mathrm{C}$ while the plates containing nutrient agar medium were incubated at $30^{\circ} \mathrm{C}$ for $48 \mathrm{hrs}$ or till the appearance of visible colonies.

In this method, the coliforms if present in the sample utilizes the lactose present in the medium to produce acid and gas. The presence of acid was indicated by the color change of the medium and the presence of gas was detected as gas bubbles collected in the inverted Durham tube present in the medium. The number of total coliform was determined by counting the number of tubes giving positive reaction. The method comprises of three consecutive tests, i.e., presumptive, confirmatory and completed tests to ensure the presence of coliform in the sample. In this method, $10 \mathrm{~mL}, 1 \mathrm{~mL}$ and $0.1 \mathrm{~mL}$ of food sample was inoculated from the original one in the test tubes and then was incubated at $37^{\circ} \mathrm{C}$ for $24 \mathrm{hrs}$ and the presence of coliform bacteria was measured. Some microorganisms other than coliforms also produce acid and gas from lactose fermentation. In order to confirm the presence of coliform, a confirmatory test was done. The inoculated lactose-broth fermentation tubes was incubated at $37^{\circ} \mathrm{C}$ and inspect gas formation after $24 \pm 2$ hrs. If no gas production was seen, further it was incubated up to a maximum of $48 \pm 3$ hrs to check gas production. The formation of gas in lactose broth and the demonstration of Gram-negative, non-spore-forming bacilli in the corresponding agar indicated the presence of a member of the coliform group in the sample examined. The absence of gas formation in lactose broth or the failure to demonstrate Gram-negative, non-sporeforming bacilli in the corresponding agar slant constitutes a negative test (absence of coliforms in the tested sample). Since some of the positive results from the confirmatory test might be false, it was desirable to do completion tests. For this, inoculum from each positive tube of the confirmatory test was streaked on a plate of EMB or Endo agar. In this process, a loopful of a sample from each positive BGLB tube was streaked onto selective medium like Eosin Methylene Blue agar or Endo's medium. One plate each is incubated at $37^{\circ} \mathrm{C}$ and another at $44.5 \pm 0.2^{\circ} \mathrm{C}$ for $24 \mathrm{hrs}$. Following incubation, all plates were examined for the presence of typical colonies. Coliforms produced colonies with a greenish metallic sheen which differentiates it from non-coliform colonies (show no sheen). The presence of typical colonies on high temperature $\left(44.5 \pm 0.2^{\circ} \mathrm{C}\right)$ indicates the presence of thermotolerant $E$. coli. 


\subsection{Chemical analysis of brine}

Sample (5 g) was taken and crushed in pestle and mortar and $10 \mathrm{~mL}$ of distilled water was added to it. The crushed product was filtered through Whatman filter No. 20. The filtrate was taken for analysis of protein, phenol content, unsaturation test, optical density, viscosity, alkaloids and vitamin B content. The total sugar was estimated colorimetrically by phenol sulphuric acid method as described by Dubois et al. (1994). The pH was determined using a $\mathrm{pH}$ meter (PHS-25, Scientific Instruments, India).

Viscosity was measured by Oswald Viscometer (BS/ $\mathrm{u}, 80-120 \mathrm{scc}$ no:119) at $32^{\circ} \mathrm{C}$ with $10 \mathrm{~mL}$ of sample and compared with water.

Specific Gravity was measured by Mettler Toledo machine (pl83-s, Scientific instrument, India) with 10 $\mathrm{mL}$ of sample and compared with water (De Man et al., 1960).

\subsubsection{Qualitative test}

\subsubsection{Phenol test}

Both the sauerkraut and mixed vegetable samples were boiled with diethyl ether for 15 mins. Then, $5 \mathrm{~mL}$ of boiled sample was mixed with $5 \mathrm{~mL}$ of distilled water and was added to ammonium hydroxide and concentrated amyl alcohol (Gunasekara, 2018).

\subsubsection{Quantitative test}

\subsubsection{Estimation of protein by LOWRY method}

Standard protein solution of $1 \mathrm{~mL}$ containing 10-100 $\mathrm{mg}$ of protein or appropriately diluted of unknown protein sample solution was added to $4 \mathrm{~mL}$ of reagent $\mathrm{D}$. After 10 mins of incubation at room temperature, $0.4 \mathrm{~mL}$ of Folin's reagent was added to the solution mix and was allowed to vortex the content immediately. The reagent blank was run with $1 \mathrm{~mL}$ of distilled water along with the standard sample. After 30 mins of incubation at room temperature read the blue color appeared at $720 \mathrm{~nm}$ in a photometer and the absorbance was recorded.

\subsubsection{Spectrophotometric analysis of folic acid}

Spectrophotometric analysis of folic acid in sauerkraut and fermented mixed vegetable was carried out according to Horwitz (1970) methods.

\subsubsection{Analysis of riboflavin (spectrofluorometer)}

Riboflavin $(25 \mathrm{~g})$ was dissolved in $50 \mathrm{~mL}$ of distilled water in a $500 \mathrm{~mL}$ of volumetric flask. Glacial acetic acid of $1 \mathrm{~mL}$ was added to it. The solution was then mixed with further $500 \mathrm{~mL}$ distilled water stirred until completely dissolve and the volume made up to $1 \mathrm{~L}$ with distilled water.
A diluted standard solution containing $5 \mu \mathrm{g} / \mathrm{mL}$ was prepared each week by diluting $10 \mathrm{~mL}$ of the stock riboflavin solution. The optical density was taken 520 nm (Sharma et al., 2016).

\subsubsection{Estimation of total flavonoid content}

Sample (stock solution) having $0.5 \mathrm{~mL}$ was mixed with $1.5 \mathrm{~mL}$ of methanol, $0.1 \mathrm{~mL}$ of $10 \%$ aluminium chloride was added. Then, $0.1 \mathrm{~mL}$ of $1 \mathrm{M}$ potassium acetate was added. Then $2.8 \mathrm{~mL}$ of distilled water was added. Incubation was done at room temperature of 30 mins. Absorbance of the sample was taken at $415 \mathrm{~nm}$. The sample was filtrated through Whatman filter paper before measuring. For the preparation of stock solution, a total of $100 \mathrm{mg}$ of sample was weighed and transferred to $10 \mathrm{~mL}$ of volumetric flask and made up the volume with method (Dubois et al., 1956).

\subsubsection{Estimation of sugar}

The total sugar in fermented vegetable was determined by the Phenol-sulfuric acid methods.

In the vial, $1 \mathrm{~mL}$ of 5 phenol was added to the sample. Concentrated $\mathrm{H}_{2} \mathrm{SO}_{4}$ of $5 \mathrm{~mL}$ was added rapidly and directly on the sample. Let the sample stand for 10 mins. After that, it was shaken well and was allowed to incubate for 30 mins. Sugar present in the sample was measured from a standard curve using different concentration of lactose solution and measuring absorption at $485 \mathrm{~nm}$ wave length (Koerner et al., 2016).

\subsubsection{Analysis of alkaloids}

The sample was prepared in a beaker and $10 \% \mathrm{CH}_{3}$ $\mathrm{COOH}$ in $\mathrm{C}_{2} \mathrm{H}_{5} \mathrm{OH}$ was added. The mixture was covered and allowed to stand for $4 \mathrm{hrs}$. The mixture was then filtered, and the extract was allowed to become concentrated in a water bath until it reaches $1 / 4^{\text {th }}$ of the original value. Concentrated $\mathrm{NH}_{4} \mathrm{OH}$ was added until the precipitation was complete. This whole solution was allowed to settle, and precipitation was collected and washed with diluted $\mathrm{NH}_{4} \mathrm{OH}$ (Mir et al., 2016).

\subsubsection{Estimation of lactic acid}

The content of titrable acidity is measured by titration using phenolphthalein indicator solution. The following formula is used to measure lactic acid:

Titrable acidity $($ as lactic acid $)=9$. A.N/W

Where $\mathrm{A}=$ Vol. in $\mathrm{mL}$ of the standard sodium hydroxide required for titration, $=$ Normality of the standard sodium hydroxide solution and $\mathrm{W}=$ Weight in gram of the sample taken for the test (Rao and Deshpande, 2005). 


\subsection{Sensory evaluation}

Twenty trained individuals tested the sauerkraut and fermented mixed vegetable at random order for the assessment of organoleptic properties i.e., color, appearance, texture, flavor, taste, and overall acceptability. Hedonic rating test was used for scoring appearance, texture, flavor, and total acceptability (Srilakshmi, 2016). The samples were stored at $-20 \pm 1^{\circ}$ C. Sensory evaluation of the fermented samples was carried out on $0,15,30,45$ and $60^{\text {th }}$ day of storage. The data were collected from each individual separately.

\section{Results}

\subsection{Physical tests}

There was a change in $\mathrm{pH}$ of both the samples (sauerkraut and fermented mixed vegetables). The rising of $\mathrm{pH}$ values meant the acid content was increased with time. The $\mathrm{pH}$ of the Sauerkraut which was almost neutral (6.9) at the start of fermentation decreased slowly to approximately 4 after 15 days of fermentation and then it became constant in all four treatments. Measurement of $\mathrm{pH}$ was at $25^{\circ} \mathrm{C}$ (Table 1 ). Viscosity and specific gravity remained unchanged even after 14 days of fermentation of both the samples (Table 1).

\subsection{Biochemical tests}

The appearance of light green color in both the sample confirmed the presence of phenol. The appearance of light violet color in both sauerkraut and fermented mixed vegetables confirmed the presence of unsaturated fatty acid. From Table 1, it was shown there was a significant difference of protein content between raw and fermented vegetables due to the fermentation. With increasing fermentation time period, the content of folic acid and riboflavin had increased in fermented mixed vegetables compared to sauerkraut as because of the synthesis of these vitamins by the microorganisms in due course of fermentation (Table 1).There was no such significant difference in alkaloid and flavonoid contents between sauerkraut and fermented vegetables whereas increased sugar content was found to occur in fermented mixed vegetables in due course of fermentation due to the synthesis of lactose by the microorganisms (Table 1).

The amount of total acids presents in brine drawn during Sauerkraut and mixed vegetable fermentation and storage was analyzed. In the sauerkraut prepared by addition of sodium chloride only, the initial total acid was found to be $0.45 \%$ that increased to $2 \%$ on $14^{\text {th }}$ day of fermentation and storage (Table 1).

\subsection{Enumeration of microorganisms}

In the onset of fermentation, the number of bacteria on nutrient agar media of both sauerkraut and fermented mixed vegetables was found to be $1.3-1.5 \times 10^{4} \mathrm{CFU} / \mathrm{mL}$. After that, the number of bacteria decreased initially to $2.0-2.4 \times 10^{3} \mathrm{CFU} / \mathrm{mL}$ on the $60^{\text {th }}$ day. Thereafter, it increased to $1.3-2.1 \times 10^{6} \mathrm{CFU} / \mathrm{mL}$ and then remained constant up to 90 days. Whereas, in the Sauerkraut and fermented mixed vegetables prepared by inoculation of L. plantarum, number of bacteria at the start of fermentation was $1.3 \times 10^{5} \mathrm{CFU} / \mathrm{mL}$ which increased to $2.3 \times 10^{6} \mathrm{CFU} / \mathrm{mL}$ and then remained constant up to 90 days.

The number of microorganisms on MRS media at the start of fermentation was found to be $2.0-2.2 \times 10^{4}$ $\mathrm{CFU} / \mathrm{mL}$ in the Sauerkraut and fermented mixed vegetables prepared without inoculation of $L$. plantarum which increased exponentially to $1.8-2.8 \times 10^{7} \mathrm{CFU} / \mathrm{mL}$ on $15^{\text {th }}$ day and remained constant thereafter. In the Sauerkraut prepared by inoculation of $L$. plantarum, the number of bacteria at the start of fermentation was 2.3$2.5 \times 10^{6} \mathrm{CFU} / \mathrm{mL}$ and then remained constant up to 90 days.

\subsection{Determination of coliforms}

No acid and gas formation were observed in the MacConkey's broth tubes (using 10,1 and $0.1 \mathrm{~mL}$ of brine as inoculum in triplicate), indicating the absence of coliforms. Similarly, the confirmatory test on EMB agar plate for enumeration of Enterobacter gave negative results. No colony having green metallic sheen was observed on the EMB agar plates. All the experiment was carried out in triplicate. This statistical analysis was done by Origin 60 and Microsoft Office Excel.

\subsection{Sensory evaluation}

The sensory evaluation of the Sauerkraut and fermented mixed vegetables prepared by different treatments was done by a panel of judges using 9-point Hedonic scale. The significant difference was observed in appearance, color, and odor of both the samples

Table 1. Biochemical parameters of sauerkraut and fermented vegetables

\begin{tabular}{|c|c|c|c|c|c|c|c|c|c|c|}
\hline Sample & $\mathrm{pH}$ & $\begin{array}{l}\text { Specific } \\
\text { gravity }\end{array}$ & $\begin{array}{c}\text { Viscosity } \\
\text { (centipoise) }\end{array}$ & $\begin{array}{l}\text { Protein } \\
(\mathrm{mg} / \mathrm{mL})\end{array}$ & $\begin{array}{c}\text { Folic acid } \\
(\mathrm{mg} / \mathrm{mL})\end{array}$ & $\begin{array}{c}\text { Riboflavin } \\
(\mathrm{mg} / \mathrm{mL})\end{array}$ & $\begin{array}{c}\text { Lactose } \\
(\mathrm{mg} / \mathrm{mL})\end{array}$ & $\begin{array}{c}\text { Flavonoid } \\
(\mathrm{mg} / \mathrm{mL})\end{array}$ & $\begin{array}{c}\text { Alkaloid } \\
(\%)\end{array}$ & $\begin{array}{c}\text { Total acidity } \\
(\%)\end{array}$ \\
\hline Sauer & 4.2 & 1.016 & 1.188 & 0.015 & 0.051 & 1.198 & 0.538 & 0.1 & 2.81 & 1.89 \\
\hline $\begin{array}{l}\text { Fermented mix } \\
\text { vegetables }\end{array}$ & 5.3 & 1.009 & 1.204 & 0.016 & 0.065 & 1.633 & 0.946 & 0.105 & 1.86 & 2.01 \\
\hline
\end{tabular}

Values are expressed as means from triplicate testing. 
Table 2. Sensory assessment of sauerkraut and fermented mix vegetables

\begin{tabular}{|c|c|c|c|c|c|}
\hline Sample & Color & Body and texture & Taste & Odor & Overall acceptability \\
\hline \multicolumn{6}{|l|}{ Sauerkraut } \\
\hline 0 days & 7.6 & 7.9 & 7.3 & 7.3 & 7.4 \\
\hline 7 days & 6.8 & 7.3 & 4.8 & 5.4 & 5.6 \\
\hline 14 days & 5.9 & 6.4 & 4.1 & 4.8 & 4.5 \\
\hline \multicolumn{6}{|c|}{ Fermented mixed vegetable } \\
\hline o days & 7.8 & 7.6 & 6.9 & 6.4 & 7.3 \\
\hline 7 days & 6.2 & 6.9 & 4.2 & 4.9 & 5.8 \\
\hline 14days & 5.4 & 5.9 & 3.8 & 4.2 & 4.2 \\
\hline
\end{tabular}

Values are expressed as means from triplicate testing.

prepared with increasing fermentation time. For taste, the score was 7.3 and 6.9, respectively, whereas in course of fermentation the score were awarded 4.8 and 4.2. For odor, the score was 7.3 and 6.4, whereas, in mixed vegetables, it was 5.4 and 4.9. Similarly, the scores by the judges in the panel for other parameters like body and texture and overall acceptability of sauerkraut and fermented mixed vegetables were recorded (Table 2).

\section{Discussion}

Cabbage typically contains 4 to $5 \%$ sugar, consisting of about $2.5 \%$ glucose and $2 \%$ fructose. During fermentation, the sugar present in cabbage diffuses in brine and concentration of sugar increases in the brine (Xiong et al., 2014). The same trend of sugar change was observed in present investigation. The initial total sugar was found to be low, but as the fermentation proceeded the soluble sugars of cabbage released in the brine and total sugar increased from $2.4 \%$ to $5.4 \%$ and $2.3 \%$ to 9.5\% after 14 days of fermentation (shown in Table 1). During storage of sauerkraut and fermented mixed vegetables in the refrigerator sugar remained constant up to 90 days. This may be due to static nature of growth of microorganisms at low temperature. The total acidity attained during cauliflower fermentation is $0.39 \%$ with a $\mathrm{pH}$ of 4.1. Likewise, in the fermentation of whole carrots an acidity of 1.1 to $1.3 \%$ with a $\mathrm{pH}$ of 3.3 has been reported by Niketic-Aleksic et al. (1973). The increase in total acidity was accompanied by decrease in $\mathrm{pH}$. In the experiment, the pattern of changes observed in terms of total acidity and $\mathrm{pH}$ are typically similar found in most of the vegetable fermentation. The total acidity attained during cauliflower fermentation is $0.39 \%$ with a $\mathrm{pH}$ of 4.1 (Table 1). The addition of different raw vegetables and L. plantarum made no difference in the pattern of amount of total sugar released and the amount of total acids produced (Pederson et al., 1969). As the fermentation proceeded the LAB became dominant. Brining vegetables for fermentation results in the production of organic acids by lactic acid bacteria (LAB) and variety of microbial compounds. Because lactic acid bacteria are more resistant to acid than the spoilage microbiota, they dominate the brined vegetable fermentation. Vitamin B contents remained almost the same after 14 days of fermentation of both sauerkraut and fermented mixed vegetables that ensured no such biosynthesis of vitamins were observed (Table 1). In this present investigation, it has been reported that $L$. plantarum eventually outcompete the other lactic acid bacteria in most of the vegetable fermentations due to its high acid tolerance (Breidt et al., 2007).

Coliforms such as E. coli which form the natural microflora of water are generally present on the surface of most of the vegetables. Since the presence of coliforms was determined only after completion of fermentation, the coliforms were not present in the Sauerkraut and fermented mixed vegetables and therefore, those prepared by fermentation were safe for human consumption.

Addition of different vegetables increased the overall acceptability of the product. The fermented mixed vegetable prepared was crispy and possessed a pleasant aroma and flavor (Table 2).

\section{Conclusion}

Based on the biochemical activity, different types of vegetable were observed to have a greater potency. Broccoli, capsicum, cabbage, carrot, bean, tomato are good sources of antioxidant, folic acid, flavonoid, riboflavin, protein, carbohydrate that were derived from our results. The high nutrient density caters to the growing demand posed by growth and prevent protein malnutrition (7-10\%) which is the most sought-after problem. Vitamin B were also enriched in due course of fermentation in the mixed vegetable. Therefore, fermented mixed vegetable was recommended to consume for health benefit on nutrient point of view.

\section{Acknowledgement}

The author acknowledges the college authority to carry on the research work properly in time. 


\section{References}

Amin, I. and Lee, W.Y. (2005). Effect of different blanching times on antioxidant properties in selected cruciferous vegetables. Journal of the Science Food and Agriculture, 85(13), 2314-2320. https:// doi.org/10.1002/jsfa.2261

Bartoszek, A., Forc, A. and Grzeskowiak, J. (2002). Antioxidative properties of some vegetable products traditional for diets in Central Europe - Short Report. Polish Journal of Food and Nutrition Sciences, 11, 67-70.

Breidt, F., McFeeters, R.F. and Díaz-Muñiz, I. (2013). Fermented vegetables. In Doyle, M.P. and Buchanan, R.L. (Ed.) Washington, D.C., USA: ASM Press.

Ciska, E. and Pathak, D.R. (2004). Glucosinolate derivatives in stored fermented cabbage. Journal of Agricultural and Food Chemistry, 52, 7938-7943. https://doi.org/10.1021/jf048986+

Davey, M. W., Montagu, M., Inze, D., Sanmartin, M., Kanellis, A. and Smirnoff, N. (2000). Review: Plant L-ascorbic acid: Chemistry, function, metabolism, bioavailability and effects of processing. Journal of the Science Food and Agriculture, 80(7), 825-860. https://doi.org/10.1002/(SICI)1097-0010(20000515) 80:7<825::AID-JSFA598>3.0.CO;2-6

De Man, Rogosa and Sharpe. (1960). 69964 Agar Agar. Applied Bacteriology, 23(1), 130-135. https:// doi.org/10.1111/j.1365-2672.1960.tb00188.x

Dubois, M., Gilles, K.A., Hamilton, J.K., Rebess, P.A. and Smith, F. (1956). Colorimetric method for determination of sugar and related substance. Analytical Chemistry, 28, 350-356. https:// doi.org/10.1021/ac60111a017

Gunasekara. A.R.J. (2018). G.C.E. (A/L) Chemistry Practical Handbook. India: National Institute of Education.

Horwitz, W. (1970). Methods of Analysis of the Association of Official Analytical Chemists, 11th ed. Washington DC, USA: AOAC.

Ivey, J. (2018). Fermented Foods: Sauerkraut. Today's Dietitian, 20, 12.

Koerner, R.M., Koerner, G.R. and Huang, W. (2016). Geotextile tubes for dewatering and decontamination of fine-grained soils. In Koerner, R.M. (Ed.) Geotextiles. USA: Woodhead Publishing. https:// doi.org/10.1016/B978-0-08-100221-6.00021-8

Mir, M.A., Parihar, K., Tabasum, U. and Kumari, E. (2016). Estimation of alkaloid, saponin and flavonoid, content in various extracts of Crocus sativa. Journal of Medicinal Plants Studies, 4(5), 171-174.
Niketic-Aleksic, G., Bourne, M. and Stamer, J. (1973). Preservation of carrots by lactic acid fermentation. Journal of Food Science, 38(1), 84-86. https:// doi.org/10.1111/j.1365-2621.1973.tb02782.x

Panesar, P.S. (2011). Fermented Products: Starter Cultures and Potential Nutritional Benefits. Food and Nutrition Sciences, 2(1), 47-51. https:// doi.org/10.4236/fns.2011.21006

Pederson, C.S. and Albury, M.N. (1969). The sauerkraut fermentation. New York: Agricultural Experiment Station.

Peñas, E., Martinez-Villaluenga, C., Frias, J., SánchezMartínez, M.J., Pérez-Corona, M.T., Madrid, Y., Cámara, C. and Vidal-Valverde, C. (2012). Se improves indole glucosinolate hydrolysis products content, Semethylselenocysteine content, antioxidant capacity and potential anti-inflammatory properties of sauerkraut. Food Chemistry, 132(2), 907-914. https://doi.org/10.1016/j.foodchem.2011.11.064

Rao, B.S. and Deshpande, V. (2005). Experimental Biochemistry: A Student Companion. $1^{\text {st }}$ ed. United Kingdom: Anshan.

Sharma, Y., Srivastava, N., Nagar, A. and Dua, D. (2016). Antibacterial activity, phytochemical screening and antioxidant activity of stem of Nicotiana tabacum. International Journal of Pharmaceutical Sciences and Research, 7(3), 115667.

Srilakshmi, B. (2016). Food Science. 3rd ed. New Delhi, India: New Age International (P) Limited Publisher.

VanGarde, S.J. and Woodburn, M.J. (1994). Food preservation and safety: principles and practice. $1^{\text {st }}$ ed. USA: Iowa State University.

Xiong, T., Li, X., Guan, Q., Peng, F. and Xie, M. (2014). Starter culture fermentation of Chinese sauerkraut: Growth, acidification and metabolic analyses. Food Control, 41, 122-127. https://doi.org/10.1016/ j.foodcont.2013.12.033 